\title{
Dielectric and Thermal Properties of Epoxy Resin Nanocomposites Containing Polyhedral Oligomeric Silsesquioxane
}

\author{
Miao Pan ${ }^{1}$, Chunling Zhang ${ }^{1}$, Bo Liu ${ }^{1} \&$ Jianxin $\mathrm{Mu}^{2}$ \\ ${ }^{1}$ College of Materials Science and Engineering, Jilin University, Changchun, PR China. \\ ${ }^{2}$ College of Chemistry, Jilin University, Changchun, PR China \\ Correspondence: Jianxin Mu, College of Chemistry, Jilin University, Changchun 130021, PR China. E-mail: \\ jianxin_mu@yahoo.com
}

Received: November 23, 2012 Accepted: December 10, 2012 Online Published: December 24, 2012

doi:10.5539/jmsr.v2n1p153

URL: http://dx.doi.org/10.5539/jmsr.v2n1p153

\begin{abstract}
Epoxy resin nanocomposites based on 3,3', 5,5' $-4,4^{\prime}$ tetramethylbiphenyl diglycidyl epoxy resins (TMBP) were prepared through in situ co-polymerization with 4, 4'-diaminodiphenylsulfone (DDS) in the presence of octapropylglycidylether silsesquioxane (OGPOSS). The thermal properties of the TMBP/OGPOSS nanocomposite were analyzed by DSC and TGA. The glass transition temperature $\left(\mathrm{T}_{\mathrm{g}}\right)$ increased with increasing OGPOSS content. Additionally, the integrity of the epoxy networks was also demonstrated by thermal decomposition which occurred in one-step. The dielectric constant decreased with the increase of OGPOSS content. The morphology of TMBP/OGPOSS hybrids was characterized by Scanning Electron Microscopy (SEM).
\end{abstract}

Keywords: epoxy resin, TMBP, POSS, nanocomposites

\section{Introduction}

Epoxy resin is a kind of thermosetting polymers, which has been commercialized in the past decades. Nowadays, there are thousands of different categories of epoxy resins available in the market. Epoxy resins are widely used as adhesive and as matrix resins for composites due to its desirable properties, such as excellent chemical resistance, low creep and good electrical insulating properties (Xu, Bao, Shen, Hang, \& He, 2003; Zhen et al., 2009; Fraga, Vazquez, Rodríguez-Núñez, \& Martínez-Ageitos, 2008; Tripathi \& Srivastava, 2009; Liu, Qiu, Wang, Huo, \& Sun, 2008; Jagadeesh et al., 2000; Liaw \& Shen, 1994). However, its low thermal resistance, relatively high moisture sensitivity etc. have limited its application. It is reported that epoxy resin can be modified by silica, carbon nanotube, and hydroxide etc. Many kinds of modified epoxy resins are used for high performance packaging materials (Kim \& Lee, 2002; Lin, Huang, \& Wang, 2002; Kim, Lu, \& Shim, 2001).

Because rigid rod epoxy resins possess good thermal-oxidation stability and excellent physical properties, they have been developed as a high performance polymer for electronic and aerospace applications (Lee, Shim, \& Kim, 2002). Owing to the rigid rod structure of 4,4'-diglycidyl (3,3',5,5'-tetramethlbiphenyl) epoxy resin (TMBP), it has great potential for good adhesion, high fracture toughness, and the feasibility of high filler loading. Su's group studied TMBP epoxy resin which was cured with aromatic diamine, anhydride and phenol novolac, respectively (Liaw \& Shen, 1994; Kim \& Lee, 2002; Lin et al., 2002; Kim et al., 2001). The results indicated cured epoxies exhibited remarkable thermal and electrical properties (Su, 1993; Su, Schoch, \& Smith, 1998; Su, Huang, \& Pan, 2002; Su, Lee, \& Pan, 2002 ).

Organic-inorganic hybrid nanocomposite materials have been considered as new generation high performance materials because they combine the advantages of inorganic materials (rigidity, high stability) and organic polymers (flexibility, dielectric, ductility, and processability). Polyhedral oligomeric silsesquioxanes (POSS) belong to the family of these new hybrid materials with cage frameworks having different degrees of symmetry (Schwab \& Lichtenhan, 1998; Pittman, Li, \& Ni, 2003) and an unique type of three-dimensional organosilicon compounds having the common formula of $\left[\mathrm{RSiO}_{3 / 2}\right]_{\mathrm{n}}$, with $\mathrm{n}$ varying from 6 to 18 (Baney, Itoh, Sakakibara, \& Suzuki, 1995; Xu, Xie, \& Zhang, 2001; Bharadwaj, Berry, \& Farmer, 2000; Wang, Lu, \& He, 2011; Marcolli \& Calzaferri, 1999; Cordes, Lickiss, \& Rataboul, 2010). Various POSS reagents have been incorporated into 
polymer matrix to form the organic-inorganic hybrid materials because of their unique stuctures (Bao, Kuck, Rogers, \& Paczkowski, 2002; Matějka et al., 2004; Lee, Kuo, Huang, Lee, \& Chang, 2004).

In this paper, we report the effect of OGPOSS on the thermal stabilty, dielectric properties, hydroscopicity, and morphology of DDS-cured epoxy nanocomposites. The conclusive properties of the hybrids were studied using different techniques, including Fourier transform infrared spectroscopy (FTIR), differential scanning calorimetry (DSC), thermogravimetric analysis (TGA), dielectric analysis, and scanning electron microscopy (SEM).

\section{Experiment}

\subsection{Materials}

The system was based on epoxy resins having the biphenyl structure unit (TMBP), with an epoxide equivalent weight of 354, synthesized and characterized according to our previously reported procedure (Zhang, Na, Liu, \& Ge, 2002; Zhang et al., 2004; Zhang et al., 2004). The OGPOSS was synthesized through the hydrolysis and condensation of 3-glycidyloxypropyltrimethoxysilane (GMPS) catalyzed by formic acid using a previously reported procedure (Lu, Liang, \& Guo, 2006). ${ }^{29} \mathrm{Si}$ Nuclear Magnetic Resonance (NMR) (ppm): -55.6, -61.1; Mass spectrum (MS) (MALDI-TOF, DHB matrix), m/z (product $+\mathrm{Na}^{+}$): 1362.5, 1695.5; Anal. Calc. for $\mathrm{C}_{48} \mathrm{H}_{88} \mathrm{O}_{28} \mathrm{Si}_{8}$ : C, 43.09\%; H, 6.63\%; O, 33.48\%; Si, 16.79\%; Found, C, 42.08\%; H, 6.49\%; O, 33.88\%; $\mathrm{Si}$, $17.55 \%$.

4,4'-diaminodiphenylsulfone (DDS) was obtained from Aladdin Chemistry Co., Ltd., Shanghai, China and used as curing agent. N,N-dimethylformamide(DMF) and formic acid were purchased from the Shenyang Xinxi Reagent Plant. Other reagents and solvents were used as received.

\subsection{Preparation of Nanocomposites}

TMBP epoxy resin nanocomposites were prepared through in situ polymerization with DDS in the presence of OGPOSS at different POSS concentration. First of all, OGPOSS was dissolved in the smallest possible amount of tetrahydrofuran (THF), subsequently, the desired amounts of TMBP were added into the solution with vigorous stirring until the system became homogeneous at room temperature. Afterwards, the stoichiometric weight of DDS was incorporated into the solution with continuous stirring at $100{ }^{\circ} \mathrm{C}$. After evaporating the majority of the solvent and degassing at $70{ }^{\circ} \mathrm{C}$ under vacuum for $30 \mathrm{~min}$ to remove the residual solvent. When the mixture became homogeneous and no more bubbles appeared, it was poured into an aluminum mold that was preheated to $120^{\circ} \mathrm{C}$. The curing process was set as follows: $150{ }^{\circ} \mathrm{C}$ for $3 \mathrm{~h}, 200{ }^{\circ} \mathrm{C}$ for $3 \mathrm{~h}$, and $220^{\circ} \mathrm{C}$ for $0.5 \mathrm{~h}$. After the mold slowly cooled, samples were taken out for testing (Scheme 1).
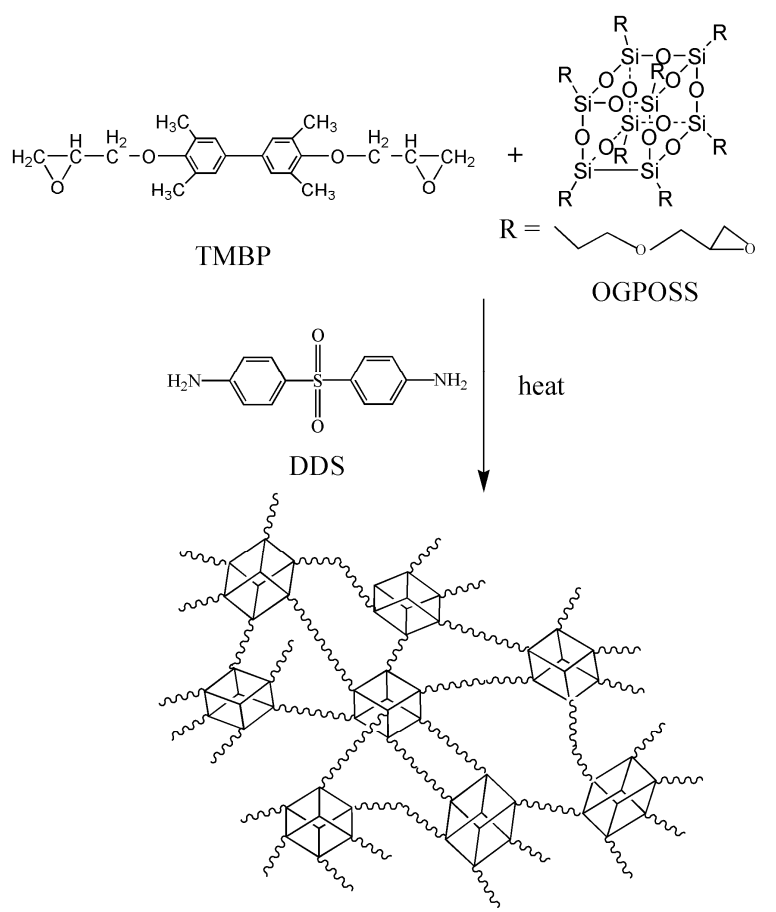

Scheme 1. The schematic of DDS-cured TMBP/OGPOSS nanocomposites 


\subsection{Measurements and Techniques}

\subsubsection{Fourier Transform Infrared Spectroscopy (FTIR)}

FTIR spectra were recorded on a Nicolet AVATAR 320 FT-IR spectrometer at room temperature $\left(27^{\circ} \mathrm{C}\right)$. The samples were mixed with $\mathrm{KBr}$ powder and pressed into the flasks. After the sample was loaded, a minimum of 32 scans were collected from each sample at a resolution of $\pm 4 \mathrm{~cm}^{-1}$.

\subsubsection{Nuclear Magnetic Resonance Spectroscopy}

The NMR measurement was conducted on a Bruke Avance $300 \mathrm{MHz}$ NMR spectrometer at $25{ }^{\circ} \mathrm{C}$. The samples were dissolved with deuterated chloroform. The ${ }^{1} \mathrm{H}$ and ${ }^{29} \mathrm{Si}$ spectra were obtained using tetramethylsilane (TMS) as reference.

\subsubsection{Mass Spectrum and Element Analyses}

Matrix-assisted UV-MALDI-TOF MS was recorded on an Applied Biosystems Voyager DE-STR device. The selected matrix was 2,5-dihydroxybenzoic acid. The elements $\mathrm{C}, \mathrm{H}$, and $\mathrm{N}$ were analyzed using Flash EA 1112 CHN.

\subsubsection{Differential Scanning Calorimetry (DSC)}

The thermal curing study of epoxy nanocomposites was performed using METTLER TOLEDO DSC $821^{\mathrm{e}}$ differential scanning calorimeter. All samples (about $5 \mathrm{mg}$ ) were subjected from $50{ }^{\circ} \mathrm{C}$ to $300{ }^{\circ} \mathrm{C}$ at a heating rate of $10{ }^{\circ} \mathrm{C} / \mathrm{min}$ under nitrogen flow of $200 \mathrm{ml} / \mathrm{min}$. The glass transition temperature was taken from the midpoint of the capacity change.

\subsubsection{Thermogravimetric Analysis (TGA)}

TGA was carried out on a Pyris TGA (Perkin-Elmer) thermal analyzer system to investigate the thermal stabilities of the hybrids under nitrogen gas atmosphere. About $5 \mathrm{mg}$ to $10 \mathrm{mg}$ samples were heated from $50{ }^{\circ} \mathrm{C}$ to $800^{\circ} \mathrm{C}$ at a heat rate of $10^{\circ} \mathrm{C} / \mathrm{min}$ in all cases.

\subsubsection{Dielectric Analysis}

The samples were coated as thin as possible with silver paint (diameter $=10 \mathrm{~mm}$ ) and dried for 12 hours for testing. The dielectric properties of the neat and the POSS-containing epoxy systems were tested using a broadband dielectric spectrometer at the platinum $(\mathrm{Pt})$ electrode at room temperature and a frequency range of $1 \mathrm{MHz}$. The experiment was repeated four times under the same conditions.

\subsubsection{Static Contact Angle and Water Uptake}

The flat free surfaces of the samples were used for measurement of contact angles. The measurements, using ultrapure water as probe liquids, were performed on an OCA20 contact angle measurement instrument (Hysics Co.) at room temperature.

In order to measure the water uptake of the samples, the fully dried membrane was immersed in water at a specified temperature for about $12 \mathrm{~h}$. Aferwards, the samples were quickly removed from water, wiped dry of excess water on the membrane surface, and measured to determine the wet mass $\left(\mathrm{W}_{\text {wet }}\right)$. The dried weight $\left(\mathrm{W}_{\text {dry }}\right)$ was obtained after the membrane was dried at $100^{\circ} \mathrm{C}$ for $12 \mathrm{~h}$ under vacuum. The water uptake was defined as follows:

$$
\text { water uptake }(\%)=\frac{\mathrm{W}_{\text {wet }}-\mathrm{W}_{\text {dry }}}{\mathrm{W}_{\text {dry }}} \times 100 \%
$$

\subsubsection{Scanning Electron Microscopy (SEM)}

In order to observe the morphological structures, the samples were fractured under cryogenic conditions using liquid nitrogen and etched by THF for $30 \mathrm{~min}$. To remove the residual solvent, the etched specimens were dried under vacuum. Prior to observation, the fractured surfaces were coated with a thin layer of gold. The samples were observed using a scanning electron microscope (XL30 ESEM FEG, FEI COMPANY) at an accelerating voltage of $15 \mathrm{kV}$.

\section{Results and Discussion}

\subsection{Fourier Transform Infrared Spectroscopy}

Figure 1 shows the FTIR spectra for several nanocomposite systems at varying amounts of OGPOSS. The pure epoxy resin and the DDS spectra were compared. The epoxy stretching frequencies of TMBP $\left(910 \mathrm{~cm}^{-1}\right)$ and OGPOSS $\left(908 \mathrm{~cm}^{-1}\right)$ were absent in the DDS-cured epoxy nanocomposites, indicating that the curing reaction of 
nanocomposites was quite complete. A strong, sharp, and symmetric Si-O-Si stretching peak at $1100 \mathrm{~cm}^{-1}$, typical of silsesquioxanes cages, which appeared epoxy/POSS systems, was absent in pure epoxy resin. The symmetric and asymmetric N-H bonds at $3300-3500 \mathrm{~cm}^{-1}$ in the DDS spectral, which were absent in all the DDS cured epoxy systems. In addition, DDS derived N-H scissoring at $1500 \mathrm{~cm}^{-1}$ to $1600 \mathrm{~cm}^{-1}$ and $\mathrm{C}=\mathrm{O}$ aroma ring absorptions at $1500 \mathrm{~cm}^{-1}$ were present in all spectra, except in that of pure epoxy resin. The FTIR results clearly indicate that the amine groups were participated in the ring opening polymerization in the POSS-containing nanocomposites, which proved to be heavily cross-linked.

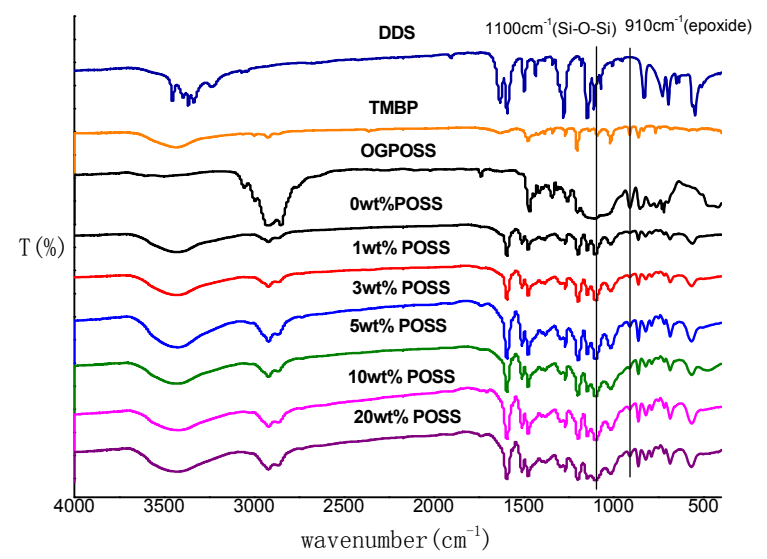

Figure 1. FTIR spectra of OGPOSS-reinforced DDS-TMBP epoxy nanocomposites

\subsection{Glass Transition Behavior}

The DSC curves of the pure epoxy and the nanocomposites are shown in Figure 2. The $\mathrm{T}_{\mathrm{g}}$ of DDS-cured TMBP was observed at $185{ }^{\circ} \mathrm{C}$. All the DSC curves of DDS-cured epoxy systems had a single glass transition temperature in the experimental temperature range. Obviously, the presence of a single $\mathrm{T}_{\mathrm{g}}$ indicates that ring-open reactions occurred between the epoxy groups in OGPOSS and epoxy resin and the amino groups in DDS. In the DDS-cured TMBP epoxy systems, the nanocomposites showed slightly higher $T_{g}$ values than that of pure epoxy, and the $\mathrm{T}_{\mathrm{g}}$ of the composites increased with increasing OGPOSS concentration. For example, $\mathrm{T}_{\mathrm{g}}$ of nanocomposite with $20 \mathrm{wt} . \%$ of OGPOSS was $219^{\circ} \mathrm{C}$. The fall of $\mathrm{T}_{\mathrm{g}}$ in nanocomposites can be attributed to two factors: the incomplete curing reaction and the increase in the free volume of the system. In the present study, epoxy stretching frequencies for TMBP $\left(910 \mathrm{~cm}^{-1}\right)$ were absent in all the DDS-cured nanocomposites, indicating a quite complete curing reaction. The decrease in the free volume is proposed to be responsible for the increased $\mathrm{T}_{\mathrm{g}}$ values because of the addition of the bulky OGPOSS cages. In addition, the composites with different loadings of OGPOSS had higer $\mathrm{T}_{\mathrm{g}}$, which may be attributed to the nano-reinforcement effect and the segmental level restriction of the motion by the incorporation of OGPOSS into the epoxy matrix, leading to increase in $T_{g}$.

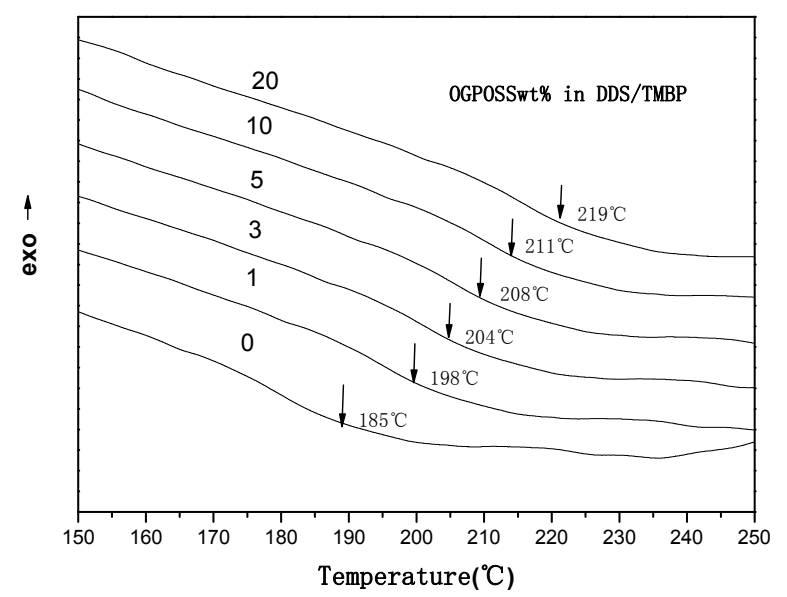

Figure 2. DSC curves of OGPOSS-reinforced DDS-cured epoxy nanocomposites 


\subsection{Thermal Stability}

Thermogravimetric analysis (TGA) was used to investigate the thermal stability of the TMBP epoxy nanocomposites. As shown in Figure 3, the TGA curves of the pure epoxy and their nanocomposites were recorded under nitrogen at $10{ }^{\circ} \mathrm{C} / \mathrm{min}$ from $50{ }^{\circ} \mathrm{C}$ to $800{ }^{\circ} \mathrm{C} . \mathrm{T}_{\mathrm{g}}, \mathrm{T}_{\mathrm{d} 5 \%}$, and $\mathrm{T}_{\mathrm{d} 10 \%}$ are shown in Table 1 . In the TMBP epoxy systems, the one-step degradation profiles that were observed suggest that the presence of OGPOSS does not change the degradation mechanism of the TMBP epoxy matrix. This is further proved by the derivative curves (Figure 4), where a sharp peak can be found in the curves of DDS-cured TMBP epoxy nanocomposites. The high $\mathrm{T}_{5 \%}$ of the TMBP systems can be attributed to the rigid biphenyl groups and bulky methyl substitutions of TMBP, having large steric hindrance effects on epoxy main chains. Covalent bonds can be assumed to have been formed in the composite systems, although nanoscale dispersion of OGPOSS cages in the epoxy matrix is also an important factor contributing to the enhanced thermal stability. Apparently, as OGPOSS content increases, the nanocomposites becomes more stable at higher temperatures.

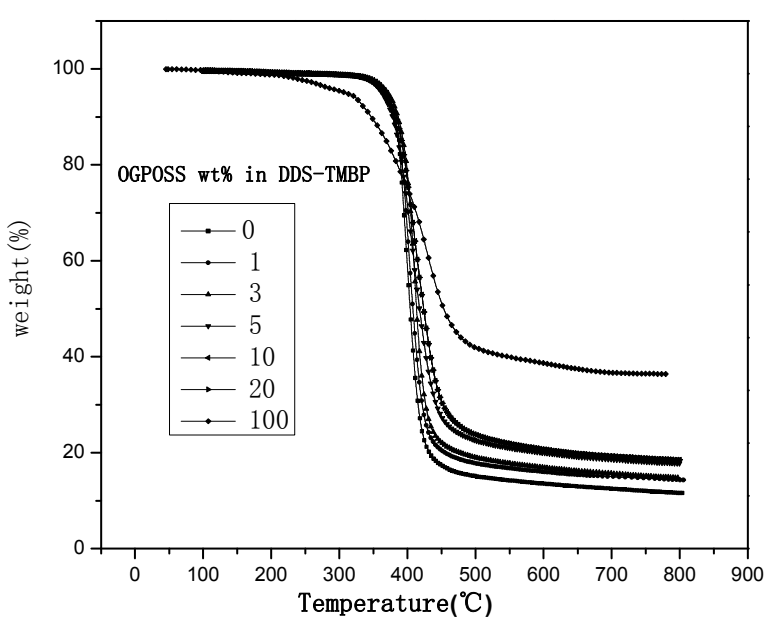

Figure 3. TGA of OGPOSS reinforced DDS-TMBP epoxy nanocomposites

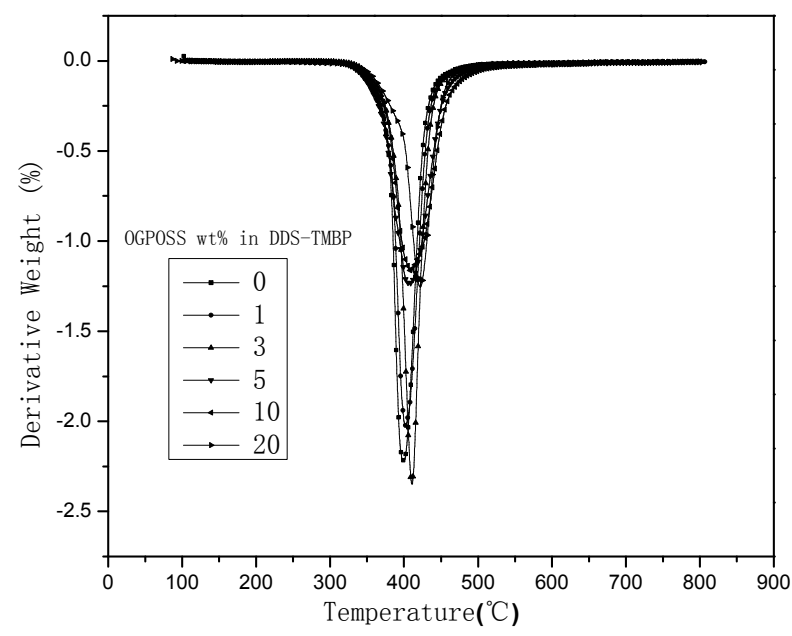

Figure 4. Plots of TGA Derivative Weight (\%) as function of temperature for OGPOSS-reinforced DDS-TMBP epoxy nanocomposites 
Table 1. $\mathrm{T}_{\mathrm{g}}, \mathrm{T}_{5 \%}$, and $\mathrm{T}_{10 \%}$ of epoxy resins with various contents of OGPOSS

\begin{tabular}{cccc}
\hline POSS $(\mathrm{wt} \%)$ & $\mathrm{T}_{\mathrm{g}}\left({ }^{\circ} \mathrm{C}\right)$ & $\mathrm{T}_{\mathrm{d} 5 \%}^{\mathrm{a}}\left({ }^{\circ} \mathrm{C}\right)$ & $\mathrm{T}_{\mathrm{d} 10 \%}^{\mathrm{b}}\left({ }^{\circ} \mathrm{C}\right)$ \\
\hline 0 & 185 & 364 & 380 \\
1 & 198 & 366 & 381 \\
3 & 204 & 371 & 386 \\
5 & 208 & 363 & 378 \\
10 & 211 & 367 & 384 \\
20 & 219 & 367 & 384 \\
\hline
\end{tabular}

a. Temperature at $5 \mathrm{wt} . \%$ weight loss

b. Temperature at $10 \mathrm{wt} . \%$ weight loss

\subsection{Dielectric Behavior}

The dielectric constants are shown in Figure 5. The incorporation of OGPOSS into the epoxy resin lead to lower dielectric behavior than that of the pure epoxy system. The dielectric constant was also found to decrease with increasing OGPOSS loadings. For the nanocomposites contained $10 \mathrm{wt} \%$ and $20 \mathrm{wt} . \%$ of OGPPOSS, the dielectric constant of the DDS-cured TMBP systems decreased from 3.84 to 3.25 and 2.76, respectively. AS the OGPOSS content increased, the nanocomposites have a downward trend in the dielectric properties, which suggests that high OGPOSS content weaken the dipole-dipole interactions in the nanocomposites. This can be attributed to the addition of the OGPOSS, which reduces the rotational freedom of the polymeric chain. In addition, the OGPOSS molecule has lower polarity, which also reduces the dielectric constant. For the advantage of molecular-level design of low dielectric constant, epoxy resin nanocomposites containing OGPOSS were prepared through in situ curing with DDS that can be used to manufacture integrated circuits.

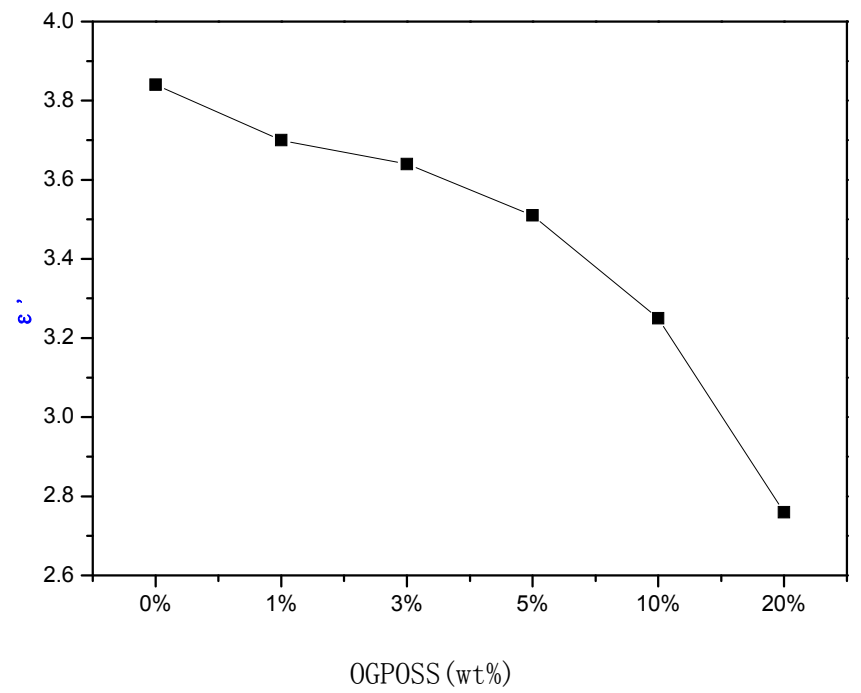

Figure 5. Dielectric constant ( $\left.\varepsilon^{\prime}\right)$ of OGPOSS reinforced DDS-TMBP epoxy nanocomposites

\subsection{Static Contact Angle and Water Uptake}

The contact angles of epoxy/OGPOSS nanocomposites were measured with water as probe liquids. The results are shown in Figure 6. The contact angle of the pure epoxy was measured with water at approximately $72^{\circ}$. With the incorporation of OGPOSS into the epoxy systems, the contact angles dramatically increased with increasing OGPOSS content. The enhanced surface contact angles indicate that the hydrophobicity of the materials is significantly improved, which can be attributed to the POSS network having low surface energy and showing hydrophobicity. 


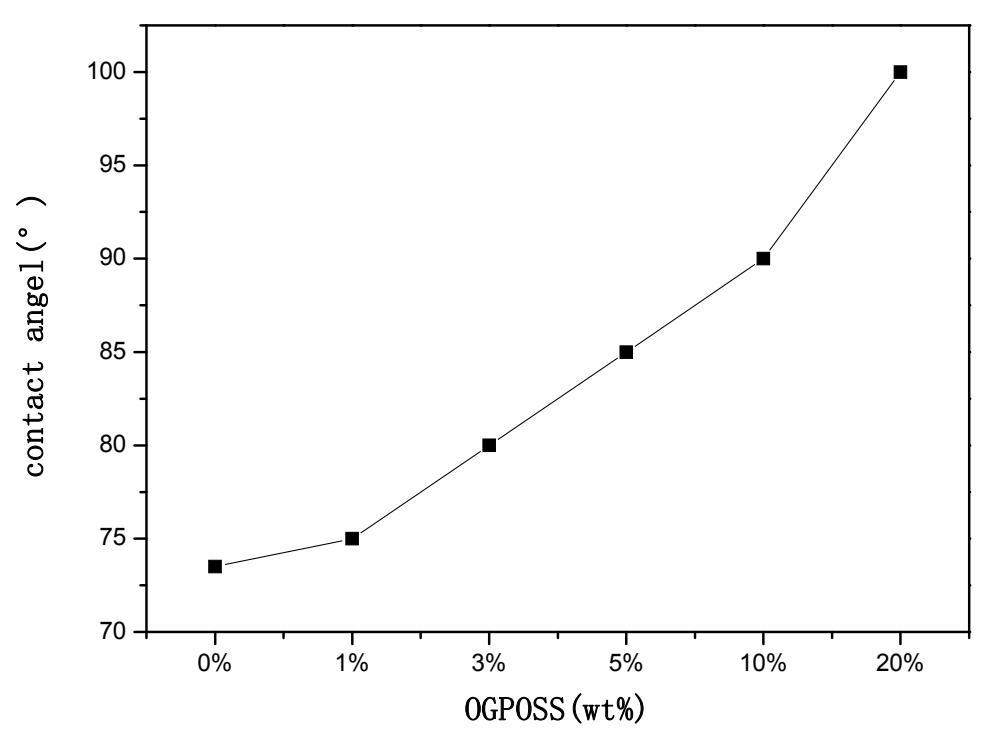

Figure 6. Static contact angle of OGPOSS reinforced DDS-TMBP epoxy nanocomposites

To evaluate water absorption changes, the water uptake of epoxy/OGPOSS nanocomposites were measured from $25{ }^{\circ} \mathrm{C}$ to $80^{\circ} \mathrm{C}$. The results are shown in Figure 7. The water uptakes increased with increasing temperature. When the temperature increased, the polymer chain mobility and the free volume for water absorption increased, resulting in increased water uptake. Moreover, water uptake decreased with increasing OGPOSS content. It can due to a highly crosslinking effect of the inorganic network, which may reduce polymer chain mobility and narrow the space where absorbed water can be accommodated.

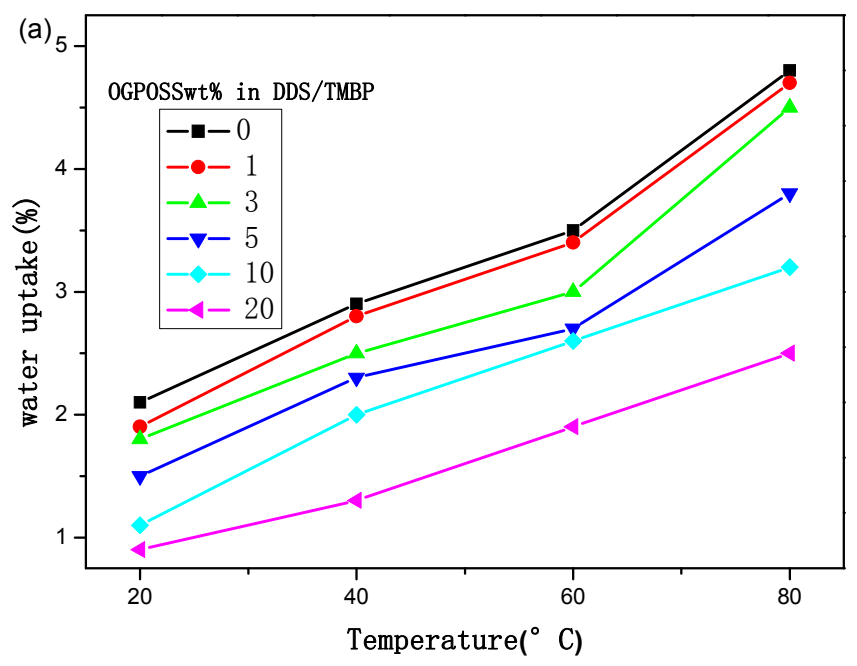

Figure 7. Water uptakes of OGPOSS reinforced DDS-TMBP epoxy nanocomposites

\subsection{Morphology of Nanocomposites}

The morphology of POSS-containing epoxy nanocomposites was further studied by SEM. Fig. 8 shows the SEM micrographs of the fracture surfaces of the nanocomposite containing $20 \mathrm{wt} \%$ OGPOSS. The result showed smooth surface in POSS-containing system. After addition of OGPOSS, the DDS-cured epoxy systems did not 
induce phase separation during the mixing and curing procedure. The SEM result suggests that OGPOSS has taken part in the formation of cross-linked epoxy networks.

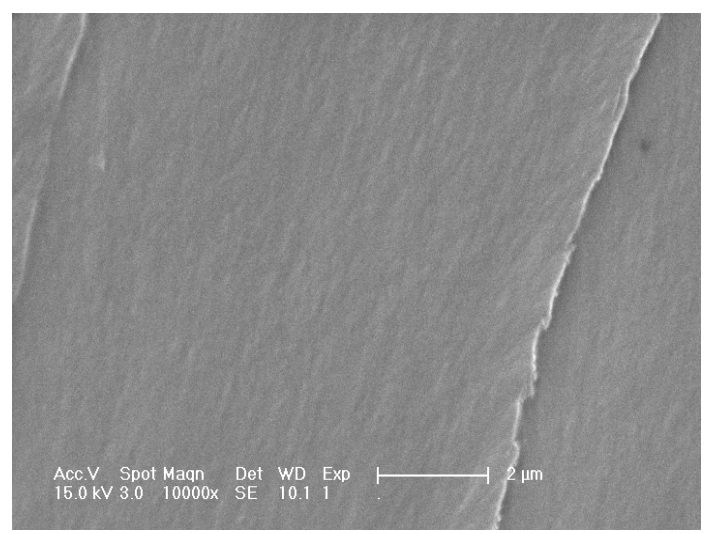

Figure 8. SEM micrographs of 20 wt.\% of OGPOSS reinforced DDS-TMBP epoxy nanocomposites

\section{Conclusion}

OGPOSS was incorporated into TMBP to prepare POSS-containing epoxy nanocomposites with DDS as curing agent. The Tg of the POSS-containing nanocomposites was higher than that of the pure epoxy resins. The main reason of the increase of $\mathrm{T}_{\mathrm{g}}$ in the nanocomposites may be due to the bulky OGPOSS cages. OGPOSS-containing epoxy nanocomposites exhibit significant improvements in thermal stability. The dielectric constant decreased with increasing OGPOSS content. The incorporation of the OGPOSS decreases the rotational freedom of the polymeric chain. In addition, the OGPOSS molecules have lower polarities, reducing the dielectric constant. The measured results of static contact angle and water uptake indicate that the nanocomposites show great improvement in surface hydrophobicity. The SEM result indicates that the dispersion of OGPOSS molecule in the epoxy matrix is homogeneous, which can be attributed to the formation of covalent bond between the OGPOSS cages and the cured epoxy networks.

\section{Ackonwledgements}

Supported by the Development Project of Jilin Province Science and Technology of China (No. 20100544) and the International Cooperative Project of Science and Technology Bureau of Chang (No. 2010064). The partial support from Natural Science Foundation of China was also acknowledged (No. 51003037).

\section{References}

Baney, R. H., Itoh, M., Sakakibara, A., \& Suzuki, T. (1995). Silsesquioxanes. Chemical Reviews, 95, 1409-1430. http://dx.doi.org/10.1021/cr00037a012

Bao, Z., Kuck, V., Rogers, J. A., \& Paczkowski, M. A. (2002). Silsesquioxane resins as high-performance solution processible dielectric materials for organic transistor applications. Advanced Functional Materials, 12, 526-531. http://dx.doi.org/10.1002/1616-3028(20020805)12:8\%3C526::AID-ADFM526\%3E3.0.CO;2-S

Bharadwaj, R. K., Berry, R. J., \& Farmer, B. L. (2000). Molecular dynamics simulation study of norbornene-POSS polymers. Polymer, 41, 7209-7221. http://dx.doi.org/10.1016/S0032-3861(00)00072-0

Cordes, D. B., Lickiss, P. D., \& Rataboul, F. (2010). Recent developments in the chemistry of cubic polyhedral oligosilsesquioxanes. Chemical Reviews, 110, 2081-2173. http://dx.doi.org/10.1021/cr900201r

Fraga, F., Vazquez, E. C., Rodríguez-Núñez E., \& Martínez-Ageitos, J. M. (2008). Curing kinetics of the epoxy system diglycidyl ether of bisphenol A/isophoronediamine by Fourier transform infrared spectroscopy. Polymers for Advanced Technologies, 19, 1623-1628.

Jagadeesh, K. S., Rao, J. G., Shashikiran, K., Suvarna, S., Ambekar, S. Y., Saletore, M., ... Rajanna, A. V. (2000). Cure Kinetics of Multifunctional Epoxies with 2,2'-Dichloro-4,4'-Diaminodiphenylmethane as $\begin{array}{lllll}\text { Hardener. Journal of Applied Polymer } & \text { Science, } & 77, & \text { 2097-2103. }\end{array}$ http://dx.doi.org/10.1002/1097-4628(20000906)77:10\%3C2097::AID-APP1\%3E3.0.CO;2-4 
Kim, S. W., Lu, M. G., \& Shim, M. J. (2001). Characteristics of medical polymer based on an epoxy resin system-curing reaction characteristics of biphenol epoxy monomer with phenolic functional hardeners. Journal of Applied Polymer Science, 82, 1495-1503. http://dx.doi.org/10.1002/app.1988

Kim, W. G., \& Lee, J. Y. (2002a). Curing characteristics of epoxy resin systems that include a biphenyl moiety. Journal of Applied Polymer Science, 86, 1942-1952. http://dx.doi.org/10.1002/app.11104

Lee, J. Y., Shim, M. J., \& Kim, S. W. (2002b). Synthesis of liquid crystalline epoxy and its mechanical and electrical characteristics-curing reaction of LCE with diamines by DSC analysis. Journal of Applied Polymer Science, 83, 2419-2425. http://dx.doi.org/10.1002/app.10204

Lee, Y. J., Kuo, S. W., Huang, W. J., Lee, H. Y., \& Chang, F. C. (2004). Miscibility, specific interactions, and self-assembly behavior of phenolic/polyhedral oligomeric silsesquioxane hybrids. Journal of Polymer Science Part B-Polymer Physics, 42, 1127-1136. http://dx.doi.org/10.1002/polb.10762

Liaw, D. J., \& Shen, W. C. (1994). Curing of acrylated epoxy resin based on bisphenol-S. Polymer Engineering and Science, 34, 1297-1303. http://dx.doi.org/10.1002/pen.760341610

Lin, C. H., Huang, J. M., \& Wang, C. S. (2002). Synthesis, characterization and properties of tetramethyl stilbene-based epoxy resins for electronic encapsulation. Polymer, 43, 2959-2967. http://dx.doi.org/10.1016/S0032-3861(02)00090-3

Liu, W. B., Qiu, Q. H., Wang, J., Huo, Z. C., \& Sun, H. (2008). Curing kinetics and properties of epoxy resin-fluorenyl diamine systems. Polymer, 49, 4399-4405. http://dx.doi.org/10.1016/j.polymer.2008.08.004

Lu, T. L., Liang, G. Z., \& Guo, Z. A. (2006). Preparation and characterization of organic-inorganic hybrid composites based on multiepoxy silsesquioxane and cyanate resin. Journal of Applied Polymer Science, 101, 3652-3658. http://dx.doi.org/10.1002/app.22743

Marcolli, C., \& Calzaferri, G. (1999). Review monosubstituted octasilasesquioxanes. Applied Organometallic Chemistry, 13, 213-226. http://dx.doi.org/10.1002/(SICI)1099-0739(199904)13:4\%3C213::AID-AOC841\%3E3.0.CO;2-G

Matějka, L., Dukh, O., Kamišová, H., Hlavatá, D., Špírková, M., \& Brus, J. (2004). Block-copolymer organic-inorganic networks. Structure, morphology and thermomechanical properties. Polymer, 45, 3267-3276. http://dx.doi.org/10.1016/j.polymer.2004.03.033

Pittman, C. U., Li, G. Z., \& Ni, H. L. (2003). Hybrid inorganic/organic crosslinked resins containing polyhedral $\begin{array}{lllll}\text { oligomeric silsesquioxanes. } & \text { Macromolecular }\end{array}$ http://dx.doi.org/10.1002/masy.200390170

Schwab, J. J., \& Lichtenhan, J. D. (1998). Polyhedral oligomeric silsesquioxane (POSS)-based polymers. $\begin{array}{llll}\text { Applied } \quad \text { Organometallic Chemistry, } & \text { 707-713. }\end{array}$ http://dx.doi.org/10.1002/(SICI)1099-0739(199810/11)12:10/11\%3C707::AID-AOC776\%3E3.0.CO;2-1

$\mathrm{Su}, \mathrm{W}$. F. (1993). Thermoplastic and thermoset main chain liquid crystal polymers prepared from biphenyl mesogen. Journal of Polymer Science Part A-Polymer Chemistry, 31, 3251-3256. http://dx.doi.org/10.1002/pola.1993.080311312

Su, W. F., Huang, H. W., \& Pan, W. P. (2002a). Thermal properties of rigid rod epoxies cured with diaminodiphenylsulfone and dicyandiamide. Thermochimica Acta, 392/393, 391-394. http://dx.doi.org/10.1016/S0040-6031(02)00125-9

Su, W. F., Lee, Y. C., \& Pan, W. P. (2002b). Thermal properties of phthalic anhydride- and phenolic resin-cured rigid rod epoxy resins. Thermochimica Acta, 392/393, 395-398. http://dx.doi.org/10.1016/S0040-6031(02)00126-0

Su, W. F., Schoch, K. F., \& Smith, J. D. B. (1998). Comparison of cure conditions for rigid rod epoxy and bisphenol A epoxy using thermomechanical analysis. Journal of Applied Polymer Science, 70, 2163-2167. http://dx.doi.org/10.1002/(SICI)1097-4628(19981212)70:11\%3C2163::AID-APP9\%3E3.0.CO;2-D

Tripathi, G., \& Srivastava, D. (2009). Cure kinetics of ternary blends of epoxy resins studied by nonisothermal DSC data. Journal of Applied Polymer Science, 112, 3119-3126. http://dx.doi.org/10.1002/app.29781

Wang, F. K., Lu, X. H., \& He, C. B. (2011). Some recent developments of polyhedral oligomeric silsesquioxane (POSS)-basedpolymeric materials. Journal of Materials Chemistry, 21, 2775-2782. http://dx.doi.org/10.1039/c0jm02785e 
Xu, H., Xie, P., \& Zhang, R. B. (2001). Synthesis and characterization of oligomeric silsesquioxane with pendent carboxylic acid groups. European Polymer Journal, 37, 2397-2405. http://dx.doi.org/10.1016/S0014-3057(01)00154-9

Xu, W. B., Bao, S. P., Shen, S. J., Hang, G. P., \& He, P. S. (2003). Curing kinetics of epoxy resin-imidazole-organic montmorillonite nanocomposites determined by differential scanning calorimetry. Journal of Applied Polymer Science, 88, 2932-2941. http://dx.doi.org/10.1002/app.12013

Zhang, C. L., Mu, J. X., Yu, W. Z., Mi, X. Y., Fu, T. Z., Pang, J. X., ... Wu, Z. W. (2004b). Curing Properties of an Epoxy Resin Containing Biphenyl Structure. Chemical Journal of Chinese Universities, 25,1937-1940.

Zhang, C. L., Na, H., Liu, C. G., \& Ge, Z. Y. (2002). Synthesis and demonstration of diglycidyl ether epoxy resin containing biphenyl. Thermosetting Resin, 17, 1-3.

Zhang, C. L., Na, H., Mu, J. X., Yu, W. Z., Fu, T. Z., Zhang, X. G., ... Wu, Z. W. (2004a). Curing Reaction Kinetics of Structure Using Epoxy Resin Containing Biphenyl DDS as Curing Agent. Chemical Journal of Chinese Universities, 25, 1756-1758.

Zhen, D., Li, Y. F., Yang, S. G., Zhao, N., Zhang, X. L., \& Xu, J. (2009). Kinetics and thermal properties of epoxy resins based on bisphenol fluorene structure. European Polymer Journal, 45, 1941-1948. http://dx.doi.org/10.1016/j.eurpolymj.2009.04.012 